\title{
Stevens-Johnson Syndrome and Toxic Epidermal Necrolysis: A Concise Review with a Comprehensive Summary of Therapeutic Interventions Emphasizing Supportive Measures
}

\author{
Jeremy A. Schneider • Philip R. Cohen
}

Received: March 1, 2017 / Published online: April 24, 2017

(C) The Author(s) 2017. This article is an open access publication

\section{ABSTRACT}

Introduction: Stevens-Johnson syndrome (SJS) and toxic epidermal necrolysis (TEN) are two of the most severe dermatologic conditions occurring in the inpatient setting. There is a lack of consensus regarding appropriate management of SJS and TEN.

Purpose: The scientific literature pertaining to SJS and TEN (subsequently referred to as SJS/ TEN) is summarized and assessed. In addition, an interventional approach for the clinician is provided.

Methods: PubMed was searched with the key words: corticosteroids, cyclosporine, etanercept, intravenous immunoglobulin, Stevens-Johnson syndrome, and toxic epidermal necrolysis. The papers generated by the search, and their references, were reviewed.

Results: Supportive care is the most universally accepted intervention for SJS/TEN. Specific guidelines differ from the care required for patients with thermal burns. Adjuvant therapies are utilized in most severe cases, but the data are thus far underwhelming and

Enhanced content To view enhanced content for this article go to http://www.medengine.com/Redeem/ 9D08F06035A59778.

J. A. Schneider · P. R. Cohen ( $\bowtie)$

Department of Dermatology, University of

California, San Diego, La Jolla, CA, USA

e-mail: mitehead@gmail.com underpowered. Using systemic corticosteroids as sole therapy is not supported. A consensus regarding combined corticosteroids and intravenous immunoglobulin (IVIG) has not been reached. Data regarding IVIG, currently the standard of care for most referral centers, is conflicting. Newer studies regarding cyclosporine and tumor necrosis factor inhibitors are promising, but not powered to provide definitive evidence of efficacy. Data regarding plasmapheresis is equivocal. Thalidomide increases mortality.

Conclusion: Clinicians who manage SJS/TEN should seek to employ interventions with the greatest impact on their patients' condition. While supportive care measures may seem an obvious aspect of SJS/TEN patient care, providers should understand that these interventions are imperative and that they differ from the care recommended for other critically ill or burn patients. While adjuvant therapies are frequently discussed and debated for hospitalized patients with SJS/TEN, a standardized management approach is not yet clear based on the current data. Therefore, until further data are available, decisions regarding such treatments should be made on a case-by-case basis.

Keywords: Corticosteroids; Cyclosporine; Dermatology; Etanercept; Immunoglobulin; Necrolysis; Johnson; Stevens; Syndrome 


\section{INTRODUCTION}

Stevens Johnson syndrome (SJS) and toxic epidermal necrolysis (TEN) can be life-threatening. They often occur as a severe adverse reaction to either a medication or, more rarely, an infection. Although systemic interventions may alter the clinical course of these conditions, supportive measures may enhance survival and expedite their resolution. The characteristics of these conditions are reviewed and the available therapies-including systemic agents and supportive management-are summarized.

This article is based on previously conducted studies and does not involve any new studies of human or animal subjects performed by any of the authors.

\section{DISCUSSION}

\section{History}

SJS was first described in 1922 by A.M. Stevens and F.C. Johnson in a report of two children with eruptive fever, stomatitis, and ophthalmia [1]. The term TEN was first coined by A. Lyell in 1956; he reported four patients presenting with "a toxic eruption which closely resembles scalding in its clinical appearance and in the sensations to which it gives rise in the patient" [2].

\section{Definition}

SJS, SJS/TEN overlap, and TEN occur along a spectrum of disease; therefore, this article shall refer to these conditions as SJS/TEN. Skin biopsy

Table 1 Classification of SJS/TEN spectrum of disease

\begin{tabular}{ll}
\hline $\begin{array}{l}\text { Disease } \\
\text { classification }\end{array}$ & $\begin{array}{l}\text { Percent of body surface area with } \\
\text { epidermal detachment }(\%)\end{array}$ \\
\hline SJS & $<10$ \\
SJS/TEN overlap & $10-30$ \\
TEN & $>30$ \\
\hline
\end{tabular}

SJS Stevens-Johnson syndrome, TEN toxic epidermal necrolysis is often essential in distinguishing SJS/TEN from clinical mimics. The characteristic pathologic finding is full-thickness epidermal necrosis. The sub-classification of SJS/TEN is based on the extent of epidermal detachment (Table 1) [3].

\section{Clinical Presentation}

SJS/TEN may manifest as erythematous or violaceous patches, atypical targetoid lesions, bullae, erosions, and ulcers. The bullae usually show a positive Nikolsky sign: slipping away of the upper layers of the skin from the lower layers when the skin is slightly rubbed. The hallmark feature of SJS/TEN is mucosal involvement (present in $80 \%$ of cases), with oral sites more commonly involved than ocular, genital, or anal mucosa [3]. Systemic symptoms, while not uniformly present, may precede skin and mucous membrane findings by 1 to 3 days. Symptoms may include pain of the skin, eyes, or other mucous membranes, headaches, rhinitis, malaise, sore throat, cough, and myalgias.

Disease severity and prognosis can be further delineated utilizing the SCORTEN criteria (Table 2) [4]. The SCORTEN criteria were introduced in 2000 by Bastuji-Garin et al. and

Table 2 SCORTEN scale

\begin{tabular}{ll}
\hline Risk factors present & Mortality rate (\%) \\
\hline $0-1$ & 3 \\
2 & 12 \\
3 & 35 \\
4 & 58 \\
$\geq 5$ & 90 \\
\hline
\end{tabular}

SCORTEN is a measure of severity of illness for toxic epidermal necrolysis. A score is determined by the number of risk factors that are present. The higher the score is, the greater the mortality rate for the patient

The presence or absence of seven risk factors is used to determine the SCORTEN: (1) age $>40$ years (2) malignancy, (3) total body surface area affected $>10$ percent, (4) heart rate $>120$ beats per minute, (5) blood urea nitrogen $>28 \mathrm{mg}$ per dl; (6) serum glucose $>250 \mathrm{mg}$ per $\mathrm{dl}$; (7) serum bicarbonate $<20 \mathrm{mEq}$ per 1 . The absence of a risk factor is scored as zero; the presence of a risk factor is scored as one. SCORTEN ranges from zero to seven 
identified seven risk factors that demonstrated excellent agreement between expected and actual mortality rates. Interestingly, one study published by some of the authors of the original SCORTEN paper found that the predictive value of the SCORTEN is most accurate when calculated on the 3rd day of hospitalization. Therefore, Guegan et al. suggest that the SCORTEN should be calculated not only on day 1 , but also on day 3 of hospitalization [5].

\section{Pathogenesis}

Our understanding of the multifaceted pathogenesis of SJS/TEN continues to evolve. A combination of drug structure and host genetic factors (such as drug metabolism, immunity, and $\mathrm{T}$ cell clonotypes) contribute to the etiology of SJS/TEN. Roujeau et al. first noted in 1987 that specific HLA molecules were responsible for recognition of culprit drugs; they elucidated the association of $H L A-B^{*} 12$ with oxicam-induced and sulfonamide-induced TEN in Europeans [6]. Subsequently, dozens of additional HLA alleles and genetic variants of cytochrome P450 2C have been associated with SJS/TEN in various ethnicities and populations. Examples include $H L A-B * 58: 01$ (association with allopurinol-related SJS/TEN); $H L A-B^{*} 15: 08, H L A-B^{*} 15: 11$, $H L A-B * 15: 18$ and HLA-A*31:01 (carbamazepine-related SJS/TEN); HLA- $B^{*} 15: 02$ (carbamazepine-, lamotrigine-, oxcarbazepine-, and phenytoin-related SJS/TEN); and $H L A-B * 51: 01$ (phenobarbital-related SJS/TEN) [7, 8]. Continued discovery and elucidation of these predisposing factors will undoubtedly play an increasing role in predicting and preventing these serious reactions in susceptible patients.

\section{Delayed Hypersensitivity}

SJS/TEN, from an immunologic standpoint, appears to behave most like a delayed-type hypersensitivity reaction (DTH) [9]. Drug or drug-peptide complexes are recognized by T-cell receptors. This results in downstream CD8+ cytotoxic T-cell and NK-cell-mediated cytotoxicity and cytokine expression [especially of tumor necrosis factor (TNF)-alpha and interferon (IFN)-gamma]. These effects drive and perpetuate the pathogenesis of SJS/TEN.

\section{Fas Ligand}

The role of cytotoxic molecules in SJS/TEN has been an important topic of research. Cytotoxic molecules provide the basis for many posited therapeutic approaches to the disease. Fas-Fas ligand (FasL) interactions were initially thought to be integral to keratinocyte apoptosis [10]. A 2003 study even demonstrated high levels of soluble FasL secretion upon drug stimulation by peripheral blood mononuclear cells obtained from TEN and SJS patients [10].

\section{Perforin and Granzyme B}

Additional studies from the early 2000s highlighted the role of perforin and granzyme $\mathrm{B}$ expression in the pathogenesis of SJS/TEN. The investigators demonstrate that inhibition of expression of perforin and granzyme B diminished cytotoxicity. They also reported that increased levels of perforin and granzyme $\mathrm{B}$ (along with those of TNF-alpha and FasL) correlated with SJS/TEN $[11,12]$.

\section{Granulysin}

Granulysin has been identified as the "key mediator" for keratinocyte death in SJS/TEN [13]. Researchers demonstrated that granulysin, produced and excreted by CD8+ and NK cells, was not only the most highly expressed cytotoxic molecule in blister fluid, but also able to induce skin changes mimicking SJS/TEN when injected into mouse skin. They also reported that depleting granulysin reduced cytotoxicity [13].

\section{Management}

\section{Supportive Care}

Identification and early withdrawal of the offending medication(s) is the most important action in caring for a patient with SJS/TEN (Table 3) [14-16]. Supportive care in a burn intensive care unit is recommended, with a focus on assessment and management of airway, renal function, fluid and electrolyte 
Table 3 A step-wise approach to patients with SJS/TEN

1 Identify and discontinue potential offending medications/drugs

2 Transfer the patient to an appropriate level of care (burn intensive care unit)

3 Wound care: nanocrystalline gauze may be preferred over petrolatum impregnated gauze as these can be left in place longer

4 Maintain the room temperature at $30-32{ }^{\circ} \mathrm{C}$

5 Monitor ins and outs of fluids and electrolytes. Replace fluid with electrolyte solution $(0.7 \mathrm{ml} / \mathrm{kg} / \%$ affected area) and albumin solution ( $5 \%$ human albumin, $1 \mathrm{ml} / \mathrm{kg} / \%$ affected area); titrate to urine output of $0.5-1 \mathrm{ml} / \mathrm{kg} / \mathrm{h}$

6 Consultations: dermatology, ophthalmology, and urology

7 Calculate SCORTEN on days 1 and 3 of hospitalization

8 Consider adjuvant systemic therapy ideally within first 24-48 $\mathrm{h}$ of presentation. These primarily include IVIG, TNF inhibitor, or cyclosporine $\mathrm{A}^{*}$

$b$ hour, $I C U$ intensive care unit, $I V I G$ intravenous immune globulin, SCORTEN score of toxic epidermal necrolysis, SJS Stevens-Johnson syndrome, TEN toxic epidermal necrolysis, $T N F$ tumor necrosis factor

* The patient's clinical status and comorbidities should be considered if adjuvant systemic therapy is being entertained

balance, nutrition, skin and ocular surfaces, pain control, and prevention of infection [14-16].

\section{Wound Care}

Consensus regarding optimal wound care has not been reached. Some centers utilize surgical debridement and whirlpool therapy [17]. In contrast, others leave detached skin in place to function as a biologic dressing; this has been referred to as "antishear wound care" [17]. The two approaches are a frequent source of disagreement between consulting specialties.
However, patients treated with either debridement or antishear wound care demonstrate equivalent rates of survival and reepithelialization [17].

Petrolatum-impregnated gauze and nonadherent nanocrystalline gauze containing silver have not been compared in a controlled fashion. In addition, neither has been compared in a controlled trial with biosynthetic skin substitutes. Certain centers may opt for one product over another based on availability, familiarity with the product(s), and decisions regarding the frequency of dressing changes. For example, nanocrystalline gauze may be left in place much longer than petrolatum-impregnated gauze, thereby reducing the frequency of dressing changes.

\section{Environment}

Despite the appearance of SJS/TEN mimicking burns, fluid, electrolyte, and nutrition requirements differ markedly from similarly sized burns. Oxygen consumption and carbon dioxide production for SJS/TEN patients were in the high-normal range compared to metabolic rates nearly twice the normal range in patients with burns of similar size. Energy requirements (in calories) for pediatric SJS/ TEN patients is estimated by the following equation: (preinjury weight $[\mathrm{kg}] \times 24.6)+$ (wound size [\% of body surface area] $\times 4.1$ ) +940 calories $[18,19]$.

\section{Fluid and Nutrition}

Fluid replacement requirements are about 30\% lower than the volumes required for burns affecting similar body surface areas. Fluid replacement with electrolyte solution $(0.7 \mathrm{ml} /$ $\mathrm{kg} / \%$ affected area) and albumin solution (5\% human albumin, $1 \mathrm{ml} / \mathrm{kg} / \%$ affected area) is recommended, titrating to maintain a urine output of $0.5-1 \mathrm{ml} / \mathrm{kg} / \mathrm{h}[20,21]$. Maintaining room temperature of $30-32^{\circ} \mathrm{C}$ has been recommended [22].

\section{Consultations}

In addition to dermatologic consultation, ophthalmologic consultation is essential. Preventive care, including lubrication, topical 
antibiotics, topical corticosteroids, lysis of adhesions, and, in severe cases, amniotic membrane transplantation, is effective in reducing ocular sequelae [23-25]. In patients with genitourinary involvement, urologic consultation is recommended. Catheterization may result in lower rates of strictures and scarring; however, infection risk should be considered and decisions regarding catheterization should be made on a case-by-case basis [26].

\section{Adjunctive Therapies}

Discussion during inpatient rounding regarding adjunctive therapies frequently consumes a disproportionate amount of time when compared to the specifics of supportive care as outlined in Table 3 [14-16]. This may occur since the data surrounding this topic are often contradictory. This article attempts to summarize the current literature regarding various adjunctive therapeutic options for SJS/TEN. However, the information in this area is continuously expanding.

\section{Systemic Corticosteroids}

Early observational studies suggested that patients treated with corticosteroids had significantly higher rates of infection (including candida sepsis) and overall complications, including higher rates of mortality [27-29]. A seemingly contradictory multicenter European study noted a "trend for a beneficial effect of corticosteroids." However, an updated analysis of the RegiSCAR study and a systematic review of case series utilizing the SCORTEN failed to demonstrate a survival advantage between patients treated with corticosteroids compared to those treated with supportive care only [30-33].

How can these contradictory observations be explained? It is possible that the early findings of increased mortality in association with corticosteroid use have changed; improved response to therapy may be a result of improved infection control, wound management, and other supportive care measures. However, based on a lack of recent evidence to support their benefit, the authors would advise against the use of corticosteroids as single-agent adjuvant therapy for SJS/TEN.

\section{Intravenous Immunoglobulin (IVIG)}

IVIG is one of the most commonly employed and consensus-approved therapies for SJS/TEN. IVIG is frequently the first adjunctive therapy utilized for severe patients seen in the tertiary care setting. However, IVIG data (of both lowand high-dose regimens) are also equivocal.

While some case reports have posited that IVIG treatment improves survival in SJS/TEN, the largest restrospective analysis of IVIG treatment in SJS/TEN concluded that IVIG did not confer a statistically significant mortality benefit compared to SCORTEN-predicted mortality [34]. Furthermore, multiple case series, meta-analyses, and systematic reviews have failed to demonstrate a statistically significant survival advantage in patients treated with IVIG when compared with supportive care alone [35-41]. In summary, while IVIG is a reasonable approach to treating patients with SJS/TEN, it is reasonable to advise prioritizing and optimizing supportive care measures and considering potential risks particular to each patient prior to initiating IVIG therapy-especially older patients and patients with renal, thrombotic, or cardiovascular disease.

\section{Tumor Necrosis Factor (TNF) Inhibitors}

Etanercept and Infliximab A small number of case reports have described treatment of SJS/ TEN with TNF inhibitors, such as infliximab and etanercept, within the last 8 years. The reports suggest that TNF inhibitors may halt progression of skin detachment and induce re-epithelialization. In addition, the agents appear to confer a survival benefit to the patients when compared to SCORTEN-predicted mortality [42-45].

Thalidomide The potential therapeutic effect of thalidomide for TEN was evaluated in a single randomized placebo-controlled trial. In contrast to the other TNF-alpha inhibitors demonstrating benefit, thalidomide increased mortality. Therefore, the trial was consequently stopped [46]. 


\section{Cyclosporine A}

Cyclosporine A, dosed at $3-5 \mathrm{mg} / \mathrm{kg}$ per day, may slow progression of SJS/TEN. Case reports and case series have noted improved survival of these patients as compared to SCORTEN predictions of SJS/TEN patients. The RegiSCAR cohort is a European registry of patients with severe cutaneous adverse reactions (SCAR) to drugs collated in an effort to study the outcome, prognostic factors, and sequelae of these reactions. Analysis of this cohort also suggested benefit; however, the small number of SJS/TEN patients treated precluded statistical significance [47-50]. Similarly, a 2017 analysis of a cohort of 44 patients ( 24 treated with cyclosporine) revealed a statistically insignificant survival benefit compared to supportive care [51].

\section{Combination Therapies}

SJS/TEN patients were treated with a combination of IVIG and corticosteroids; however, the supporting data are equivocal [52-55]. Combination therapy for SJS/TEN has been compared to SCORTEN mortality prediction, IVIG alone, and corticosteroid alone therapy. A statistically insignificant mortality benefit was observed. Hence, these observations highlight the need for further studies [52-55].

The combination of infliximab and highdose IVIG was used to successfully treat an elderly patient with TEN. A 74-year-old female received trimethoprim-sulfamethoxazole for a urinary tract infection and developed TEN (SCORTEN 3). She received a bolus of methylprednisolone $500 \mathrm{mg}$ IV followed by infliximab $5 \mathrm{mg} / \mathrm{kg}$ IV and intravenous immunoglobulin $2 \mathrm{~g} / \mathrm{kg}$ over 5 days. Her skin condition stabilized by the 2nd day of hospitalization and was noted to improve rapidly, with successful discharge on day 19 and no sequelae at 9 months [56].

\section{Plasmapheresis}

There are a few series and individual case reports, published between 1985-2002, that suggested that plasmapheresis may be beneficial for SJS/TEN. However, there were no statistically significant improvements in mortality, length of stay, or re-epithelialization [57-62].

\section{RECENT DEVELOPMENTS}

The state of the art in the management of SJS/ TEN continues to evolve based on clinical practices and retrospective evaluation of previously treated patients. A 2016 summary and list of guidelines for management of SJS/TEN was published in the UK; it also confirms that, as yet, there is no active therapeutic regimen with unequivocal benefit [63].

\section{CONCLUSION}

The definitive management of SJS/TEN remains to be established. The importance of supportive care and identification and withdrawal of potential offending drugs is underscored; these are the measures that provide the most proven benefit to SJS/TEN patients. It is incumbent on the consulting subspecialists to make these supportive care recommendations clear as they differ from the protocol employed for burn patients with the same body surface involvement. Unfortunately, the data regarding adjunctive systemic therapy are, thus far, underwhelming. TNF inhibitors (such as etanercept and infliximab) and cyclosporine $\mathrm{A}$ are promising potential therapies. It is worth noting that the treatment outcomes for cyclosporine, etanercept, and infliximab have been unidirectional (have only shown benefit) compared with conflicting outcomes described with many of the other adjunctive therapies. From a pathophysiologic standpoint, their use should be efficacious. However, randomized controlled trials have yet to provide definitive evidence of improved outcomes with these agents. Table 3 provides a concise listing of recommendations that can be utilized when caring for patients with SJS/TEN.

\section{ACKNOWLEDGEMENTS}

No funding or sponsorship was received for this study or publication of this article. All named authors meet the International Committee of Medical Journal Editors (ICMJE) criteria for 
authorship for this manuscript, take responsibility for the integrity of the work as a whole, and have given final approval for the version to be published.

Disclosures. The authors, Jeremy A. Schneider, MD, and Philip R. Cohen, MD, have nothing to disclose.

Compliance with Ethics Guidelines. This article is based on previously conducted studies and does not involve any new studies of human or animal subjects performed by any of the authors.

Open Access. This article is distributed under the terms of the Creative Commons Attribution-NonCommercial 4.0 International License (http://creativecommons.org/licenses/ by-nc/4.0/), which permits any noncommercial use, distribution, and reproduction in any medium, provided you give appropriate credit to the original author(s) and the source, provide a link to the Creative Commons license, and indicate if changes were made.

\section{REFERENCES}

1. Stevens AM, Johnson FC. A new eruptive fever associated with stomatitis and ophthalmia. Am J Dis Child. 1922;24:526-33. doi:10.1001/archpedi. 1922.04120120077005 (PMID: 14454420).

2. Lyell A. Toxic epidermal necrolysis: an eruption resembling scalding of the skin. $\mathrm{Br} \mathrm{J}$ Dermatol. 1956;68(11):355-61. doi:10.1111/j.1365-2133. 1956.tb12766.x (PMID: 13374196).

3. Chung WH, Wang CW, Dao RL. Severe cutaneous adverse drug reactions. J Dermatol. 2016;43(7):758-66. doi:10.1111/1346-8138.13430 (PMID: 27154258).

4. Bastuji-Garin S, Fouchard N, Bertocchi M, Roujeau JC, Revuz J, Wolkenstein P. SCORTEN: a severity-of-illness score for toxic epidermal necrolysis. J Invest Dermatol. 2000;115(2):149-53. doi:10.1046/ j.1523-1747.2000.00061.x (PMID: 10951229).

5. Guegan S, Bastuji-Garin S, Poszepczynska-Guigne E, Roujeau JC, Revuz J. Performance of the SCORTEN during the first five days of hospitalization to predict the prognosis of epidermal necrolysis. J Invest
Dermatol. 2006;126(2):272-6. doi:10.1038/sj.jid. 5700068 (PMID: 16374461).

6. Rojeau JC, Huynh TN, Bracq C, Guillaume JC, Revuz J, Touraine R. Genetic susceptibility to toxic epidermal necrolysis. Arch Dermatol. 1987;123(9):1171-3. doi:10.1001/archderm.1987. 01660330082014 (PMID: 3477129).

7. Saito Y, Kodama S, Sugiyama E, Nakamura R. Predictive genomic markers for severe adverse drug reactions. Yakugaku Zasshi. 2015;135(4):589-95. doi:10.1248/yakushi.14-00249-3 25832839).

8. Cheng CY, Su SC, Chen CH, Chen WL, Deng ST, Chung WH. HLA associations and clinical implications in T-cell mediated drug hypersensitivity reactions: an updated review. J Immunol Res. 2014;2014:565320. doi: $10.1155 / 2014 / 565320$ (PMID: 24901010).

9. Su SC, Chung WH. Cytotoxic proteins and therapeutic targets in severe cutaneous adverse reactions. Toxins. 2014;6(1):194-210. doi:10.3390/ toxins6010194 (PMID: 24394640).

10. Abe R, Shimizu T, Shibaki A, Nakamura H, Watanabe $\mathrm{H}$, Shimizu H. Toxic epidermal necrolysis and Stevens-Johnson syndrome are induced by soluble Fas ligand. Am J Pathol. 2003;162(5):1515-20. doi:10.1016/S0002-9440(10)64284-8

(PMID: 12707034).

11. Nassif A, Bensussan A, Dorothee G, Mami-Chouaib F, Bachot N, Bagot M, Boumsell L, Roujeau JC. Drug specific cytotoxic T-cells in the skin lesions of a patient with toxic epidermal necrolysis. J Invest Dermatol. 2002;118(4):728-33. doi:10.1046/j.15231747.2002.01622.x (PMID: 11918724).

12. Posadas SJ, Padial A, Torres MJ, Mayorga C, Leyva L, Sanchez E, Alvarez J, Romano A, Juarez C, Blanca M. Delayed reactions to drugs show levels of perforin, granzyme B, and Fas-L to be related to disease severity. J Allergy Clin Immunol. 2002;109(1):155-61. doi:10.1067/mai.2002.120563 (PMID: 11799383).

13. Chung WH, Hung SI, Yang JY, Su SC, Huang SP, Wei CY, Chin SW, Chiou CC, Chu SC, Ho HC, Yang $\mathrm{CH}, \mathrm{Lu} \mathrm{CF}, \mathrm{Wu} \mathrm{JY}$, Liao YD, Chen YT. Granulysin is a key mediator for disseminated keratinocyte death in Stevens-Johnson syndrome and toxic epidermal necrolysis. Nat Med. 2008;14(12):1343-50. doi:10. 1038/nm.1884 (PMID: 19029983).

14. Chave TA, Mortimer NJ, Sladden MJ, Hall AP, Hutchinson PE. Toxic epidermal necrolysis: current evidence, practical management and future directions. Br J Dermatol. 2005;153:241-53. doi:10.1111/ j.1365-2133.2005.06721.x (PMID: 16086734). 
15. Endorf FW, Cancio LC, Gibran NS. Toxic epidermal necrolysis clinical guidelines. J Burn Care Res. 2008;29:706-12. doi:10.1097/BCR.0b013e3181 848bb1 (PMID: 18695603).

16. Fernando SL. The management of toxic epidermal necrolysis. Australas J Dermatol. 2012;53:165-71. doi:10.1111/j.1440-0960.2011.00862.x

(PMID: 22881464).

17. Dorafshar AH, Dickie SR, Cohn AB, Aycock JK, O'Connor A, Tung A, Gottlieb LJ. Antishear therapy for toxic epidermal necrolysis: an alternative treatment approach. Plast Reconstr Surg. 2008;122(1):154. doi:10.1097/PRS.0b013e3181 773d5d (PMID: 18594400).

18. Mayes T, Gottschlich M, Khoury J, Warner P, Kagan R. Energy requirements of pediatric patients with Stevens-Johnson syndrome and toxic epidermal necrolysis. Nutr Clin Pract. 2008;23(5):547. doi:10. 1177/0884533608323434 (PMID: 18849560).

19. Heimbach DM, Engrav LH, Marvin JA. Toxic epidermal necrolysis: a step forward in treatment. JAMA. 1987;257(16):2171-5. doi:10.1001/jama. 1987.03390160057026 (PMID: 3560397).

20. Mockenhaupt M. Stevens-Johnson syndrome and toxic epidermal necrolysis: clinical patterns, diagnostic considerations, etiology, and therapeutic management. Semin Cutan Med Surg. 2014;33(1):10-6. doi:10.12788/j.sder.0058 (PMID: 25037254).

21. Shiga S, Cartotto R. What are the fluid requirements in toxic epidermal necrolysis? J Burn Care Res. 2010;31(1):100-4. doi:10.1097/BCR.0b013e3181 cb8cb8 (PMID: 20061843).

22. Letko E, Papaliodis DN, Papaliodis GN, Daoud YJ, Ahmed AR, Foster CS. Stevens-Johnson syndrome and toxic epidermal necrolysis a review of the literature. Ann Allergy Asthma Immunol. 2005;94(4):419. doi:10.1016/S1081-1206(10)61112X (PMID: 15875523).

23. Pereira FA, Mudgil AV, Rosmarin DM. Toxic epidermal necrolysis. J Am Acad Dermatol. 2007;56:181-200. doi:10.1016/j.jaad.2006.04.048 (PMID: 17224365).

24. Gregory DG. Treatment of acute Stevens-Johnson syndrome and toxic epidermal necrolysis using amniotic membrane: a review of 10 consecutive cases. Ophthalmology. 2011;118:908-14. doi:10. 1016/j.ophtha.2011.01.046 (PMID: 21440941).

25. Hazin R, Ibrahimi OA, Hazin MI, Kimyai-Asadi A. Stevens-Johnson syndrome: pathogenesis diagnosis, and management. Ann Med. 2008;40:129-38. doi:10. 1080/07853890701753664 (PMID: 18293143).
26. Downey A, Jackson C, Harun N, Cooper A. Toxic epidermal necrolysis: review of pathogenesis and management. J Am Acad Dermatol. 2012;66:995-1003. doi:10.1016/j.jaad.2011.09.029 (PMID: 22169256).

27. Ginsburg CM. Stevens-Johnson syndrome in children. Pediatr Infect Dis. 1982;1(3):155-8 (PMID: 7145729).

28. Halebian PH, Corder VJ, Madden MR, Finklestein JL, Shires GT. Improved burn center survival of patients with toxic epidermal necrolysis managed without corticosteroids. Ann Surg. 1986;204(5):503-12. doi:10.1097/00000658198611000-00001 (PMID: 3767483).

29. Kelemen JJ 3rd, Cioffi WG, McManus WF, Mason AD Jr, Pruitt BA Jr. Burn center care for patients with toxic epidermal necrolysis. J Am Coll Surg. 1995;180(3):273-8 (PMID: 7874336).

30. Schneck J, Fagot JP, Sekula P, Sassolas B, Roujeau JC, Mockenhaupt $M$. Effects of treatments on the mortality of Stevens-Johnson syndrome and toxic epidermal necrolysis: A retrospective study on patients included in the prospective EuroSCAR Study. J Am Acad Dermatol. 2008;58(1):33. doi:10. 1016/j.jaad.2007.08.039 (PMID: 17919775).

31. Finkelstein Y, Soon GS, Acuna P, George M, Pope E, Ito S, Shear NH, Koren G, Shannon MW, Garcia-Bournissen F. Recurrence and outcomes of Stevens-Johnson syndrome and toxic epidermal necrolysis in children. Pediatrics. 2011;128(4):723. doi:10.1542/peds.2010-3322 (PMID: 21890829).

32. Sekula P, Dunant A, Mockenhaupt M, Naldi L, Bouwes Bavinck JN, Halevy S, Kardaun S, Sidoroff A, Liss Y, Schumacher M, Roujeau JC, RegiSCAR study group. Comprehensive survival analysis of a cohort of patients with Stevens-Johnson syndrome and toxic epidermal necrolysis. J Invest Dermatol. 2013;133(5):1197-204. doi:10.1038/jid.2012.510 (PMID: 23389396).

33. Roujeau JC, Bastuji-Garin S. Systematic review of treatments for Stevens-Johnson syndrome and toxic epidermal necrolysis using the SCORTEN score as a tool for evaluating mortality. Ther Adv Drug Saf. 2011;2(3):87. doi:10.1177/ 2042098611404094 (PMID: 25083204).

34. Lee HY, Lim YL, Thirumoorthy T, Pang SM. The role of intravenous immunoglobulin in toxic epidermal necrolysis: a retrospective analysis of 64 patients managed in a specialized centre. Br J Dermatol. 2013;169(6):1304-9. (PMID: 24007192). doi:10.1111/bjd.12607

35. Huang YC, Li YC, Chen TJ. The efficacy ofi ntravenous immunoglobulin for the treatment of toxic 
epidermal necrolysis: a systematic review and meta-analysis. Br J Dermatol. 2012;167(2):424-32. doi:10.1111/j.1365-2133.2012.10965.X (PMID: 22458671).

36. Metry DW, Jung P, Levy ML. Use of intravenous immunoglobulin in children with Stevens-Johnson syndrome and toxic epidermal necrolysis: seven cases and review of the literature. Pediatrics. 2003;112(6 Pt 1):1430 (PMID: 14654625).

37. Prins C, Vittorio C, Padilla RS, Hunziker T, Itin P, Förster J, Bröcker EB, Saurat JH, French LE. Effect of high-dose intravenous immunoglobulin therapy in Stevens-Johnson syndrome: a retrospective, multicenter study. Dermatology. 2003;207(1):96. doi:10. 1159/000070957 (PMID: 12835566).

38. Faye O, Roujeau JC. Treatment of epidermal necrolysis with high-dose intravenous immunoglobulins (IVIg): clinical experience to date. Drugs. 2005;65(15):2085 (PMID: 16225365).

39. Morici MV, Galen WK, Shetty AK, Lebouef RP, Gouri TP, Cowan GS, Gedalia A. Intravenous immunoglobulin therapy for children with Stevens-Johnson syndrome. J Rheumatol. 2000;27(10):2494 (PMID: 11036849).

40. Bachot N, Revuz J, Roujeau JC. Intravenous immunoglobulin treatment for Stevens-Johnson syndrome and toxic epidermal necrolysis: a prospective noncomparative study showing no benefit on mortality or progression. Arch Dermatol. 2003;139(1):33-6. doi:10.1001/archderm.139.1.33 (PMID: 12533161).

41. Brown KM, Silver GM, Halerz M, Walaszek P, Sandroni A, Gamelli RL. Toxic epidermal necrolysis: does immunoglobulin make a difference? J Burn Care Rehabil. 2004;25(1):81-8. doi:10.1097/01. BCR.0000105096.93526.27 (PMID: 14726744).

42. Wojtkiewicz A, Wysocki M, Fortuna J, Chrupek M, Matczuk M, Koltan A. Beneficial and rapid effect of infliximab on the course of toxic epidermal necrolysis. Acta Derm Venereol. 2008;88(4):420-1. doi:10.2340/00015555-0462 (PMID: 18709327).

43. Patmanidis K, Sidiras A, Dolianitis K, Simelidis D, Solomonidis C, Gaitanis G, Bassukas ID. Combination of infliximab and high-dose intravenous immunoglobulin for toxic epidermal necrolysis: successful treatment of an elderly patient. Case Rep Dermatol Med. 2012;2012:915314. doi:10.1155/ 2012/915314 (PMID: 23259092).

44. Zárate-Correa LC, Carrillo-Gómez DC, Ramírez-Escobar AF, Serrano-Reyes C. Toxic epidermal necrolysis successfully treated with infliximab. J Investig Allergol Clin Immunol. 2013;23(1):61-3 (PMID: 23653980).
45. Scott-Lang V, Tidman M, McKay D. Toxic epidermal necrolysis in a child successfully treated with infliximab. Pediatr Dermatol. 2014;31(4):532. doi:10.1111/pde.12029 (PMID: 23072342).

46. Wolkenstein P, Latarjet J, Roujeau JC, Duguet C, Boudeau S, Vaillant L, Maignan M, Schuhmacher $\mathrm{MH}$, Milpied B, Pilorget A, Bocquet $\mathrm{H}$, Brun-Buisson C, Revuz J. Randomised comparison of thalidomide versus placebo in toxic epidermal necrolysis. Lancet. 1998;352(9140):1586. doi:10.1016/S01406736(98)02197-7 (PMID: 9843104).

47. Valeyrie-Allanore L, Wolkenstein P, Brochard L, Ortonne N, Maître B, Revuz J, Bagot M, Roujeau JC. Open trial of ciclosporin treatment for Stevens-Johnson syndrome and toxic epidermal necrolysis. Br J Dermatol. 2010;163(4):847. doi:10. 1111/j.1365-2133.2010.09863.x (PMID: 20500799).

48. Sekula P, Dunant A, Mockenhaupt M, Naldi L, Bouwes Bavinck JN, Halevy S, Kardaun S, Sidoroff A, Liss Y, Schumacher M, Roujeau JC, RegiSCAR study group. Comprehensive survival analysis of a cohort of patients with Stevens-Johnson syndrome and toxic epidermal necrolysis. J Invest Dermatol. 2013;133(5):1197-204. doi:10.1038/jid.2012.510 (PMID: 23389396).

49. Kirchhof MG, Miliszewski MA, Sikora S, Papp A, Dutz JP. Retrospective review of Stevens-Johnson syndrome/toxic epidermal necrolysis treatment comparing intravenous immunoglobulin with cyclosporine. J Am Acad Dermatol. 2014;71(5):941. doi:10.1016/j.jaad.2014.07.016 (PMID: 25087214).

50. Kumar P, Kanti Das N. Cyclosporine in toxic epidermal necrolysis: a brief review of the emerging therapeutic modality. Dermatol Online J. 2016;22(10).

51. Lee HY, Fook-Chong S, Koh HY, Thirumoorthy T, Pang SM. Cyclosporine treatment for Stevens-Johnson syndrome/toxic epidermal necrolysis: retrospective analysis of a cohort treated in a specialized referral center. J Am Acad Dermatol. 2017;76(1):106-13. doi:10.1016/j.jaad.2016.07.048 (PMID: 27717620).

52. Aihara M, Kano Y, Fujita H, Kambara T, Matsukura S, Katayama I, Azukizawa H, Miyachi Y, Endo Y, Asada H, Miyagawa F, Morita E, Kaneko S, Abe R, Ochiai T, Sueki H, Watanabe H, Nagao K, Aoyama Y, Sayama K, Hashimoto K, Shiohara T, SJS/TEN Study Group. Efficacy of additional i.v. immunoglobulin to steroid therapy in Stevens-Johnson syndrome and toxic epidermal necrolysis. J Dermatol. 2015;42(8):768-77. doi:10. 1111/1346-8138.12925 (PMID: 25982480).

53. Zhu QY, Ma L, Luo XQ, Huang HY. Toxic epidermal necrolysis: performance of SCORTEN and the 
score-based comparison of the efficacy of corticosteroid therapy and intravenous immunoglobulin combined therapy in China. J Burn Care Res. 2012;33(6):e295-308. doi:10.1097/BCR. Ob013e318254d2ec (PMID: 22955159).

54. Schneck J, Fagot JP, Sekula P, Sassolas B, Roujeau JC, Mockenhaupt $M$. Effects of treatments on the mortality of Stevens-Johnson syndrome and toxic epidermal necrolysis: a retrospective study on patients included in the prospective EuroSCAR Study. J Am Acad Dermatol. 2008;58(1):33. doi:10. 1016/j.jaad.2007.08.039 (PMID: 17919775).

55. Jagadeesan S, Sobhanakumari K, Sadanandan SM, Ravindran S, Divakaran MV, Skaria L, Kurien G. Low dose intravenous immunoglobulins and steroids in toxic epidermal necrolysis: a prospective comparative open-labelled study of 36 cases. Indian J Dermatol Venereol Leprol. 2013;79(4):506. doi:10. 4103/0378-6323.113080 (PMID: 23760320).

56. Patmanidis K, Sidiras A, Dolianitis K, Simelidis D, Solomonidis C, Gaitanis G, Bassukas ID. Combination of infliximab and high-dose intravenous immunoglobulin for toxic epidermal necrolysis: successful treatment of an elderly patient. Case Rep Dermatol Med. 2012;2012:915314. doi:10.1155/ 2012/915314 (PMID: 23259092).

57. Kamanabroo D, Schmitz-Landgraf W, Czarnetzki BM. Plasmapheresis in severe drug-induced toxic epidermal necrolysis. Arch Dermatol. 1985;121(12):1548. doi:10.1001/archderm.1985. 01660120074023 (PMID: 4062337).

58. Sakellariou G, Koukoudis P, Karpouzas J, Alexopoulos E, Papadopoulou D, Chrisomalis F, Skenteris N, Tsakaris D, Papadimitriou M. Plasma exchange (PE) treatment in drug-induced toxic epidermal necrolysis (TEN). Int J Artif Organs. 1991;14(10):634 (PMID: 1748531).

59. Chaidemenos GC, Chrysomallis F, Sombolos K, Mourellou O, Ioannides D, Papakonstantinou M. Plasmapheresis in toxic epidermal necrolysis. Int J Dermatol. 1997;36(3):218. doi:10.1046/j.13654362.1997.00192.x (PMID: 9159011).

60. Egan CA, Grant WJ, Morris SE, Saffle JR, Zone JJ. Plasmapheresis as an adjunct treatment in toxic epidermal necrolysis. J Am Acad Dermatol. 1999;40(3):458. doi:10.1016/S0190-9622(99)704974 (PMID: 10071318).

61. Bamichas G, Natse T, Christidou F, Stangou M, Karagianni A, Koukourikos S, Chaidemenos G, Chrysomallis F, Sombolos K. Plasma exchange in patients with toxic epidermal necrolysis. Ther Apher. 2002;6(3):225. doi:10.1046/j.1526-0968. 2002.00409.x (PMID: 12109948).

62. Furubacke A, Berlin G, Anderson C, Sjöberg F. Lack of significant treatment effect of plasma exchange in the treatment of drug-induced toxic epidermal necrolysis? Intensive Care Med. 1999;25(11):1307. doi:10.1007/s001340051063 (PMID: 10654219).

63. Creamer D, Walsh SA, Dziewulski P, Exton LS, Lee HY, Dart JK, Setterfield J, Bunker CB, Ardern-Jones MR, Watson KM, Wong GA, Philippidou M, Vercueil A, Martin RV, Williams G, Shah M, Brown D, Williams P, Mohd Mustapa MF, Smith CH. UK guidelines for the management of Stevens-Johnson syndrome/toxic epidermal necrolysis in adults 2016. J Plast Reconstr Aesthet Surg. 2016;69(6):e119-53. doi:10.1016/j.bjps.2016.01. 034 (PMID: 27287213). 